\title{
O TERCEIRO MUNDO COMO UM PROBLEMA FILOSÓFICO ${ }^{1}$
}

\author{
Vittorio Hösle \\ Tradução por Gabriel Almeida Assumpção ${ }^{2}$ \\ Universidade Federal de Minas Gerais (UFMG) \\ https://orcid.org/0000-0003-0457-6640
}

Meu título pode soar estranho por dois motivos. Primeiro, pode-se negar que o conceito de "terceiro mundo" seja legítimo. Após a dissolução do Pacto de Varsóvia, parece haver apenas dois mundos - o mundo dos pobres e o dos ricos - e a questão política fundamental nos próximos anos parece ser se os países do leste europeu e a União Soviética serão parte do primeiro ou do ainda tão-chamado terceiro mundo (o qual deveria, então, ser rebatizado "segundo mundo"). Além disso, o uso da palavra "mundo" é altamente questionável - aliás, implica que os mundos diferentes têm autonomia e perde de vista que todos os seres humanos vivem em um e apenas um mundo independente. Finalmente, a aplicação de números ordinais diferentes para mundos diferentes serve, claramente, não apenas para fins de nomenclatura. Tal aplicação sugere que o primeiro mundo é, de alguma forma, superior ao terceiro, e é o télos do terceiro mundo se aproximar do primeiro. Isso é, de qualquer maneira, implícito em termos como "países em desenvolvimento" e "países desenvolvidos"3.

No entanto, mesmo se pudéssemos ter sucesso na elaboração de um conceito melhor para essa complexa realidade à qual, normalmente, nos referiríamos pelo termo "terceiro mundo", uma segunda questão surgiria: Por que essa realidade constitui um problema filosófico? Pode-se prontamente conceder que economistas, sociólgoos, cientistas políticos, antropólogos, um número crescente de cientistas naturais, principalmente

\footnotetext{
${ }^{1}$ Originalmente publicado como "The Third World as a Philosophical Problem", em Social Research 59 (1992), 227-62, e republicado, também como "The Third World as a Philosophical Problem", no livro Objective idealism, ethics and politics (Notre Dame University Press, 1998, p. 127-151 (N. do T.).

${ }^{2}$ Mestrando em Filosofia pela Universidade Federal de Minas Gerais (UFMG), Minas Gerais - Brasil. Bolsista do CNPQ. Agradeço ao autor pela permissão para traduzir o artigo. (N. do T.)

3 Por "países em desenvolvimento" ou "países do terceiro mundo" eu entendo esses países da África, da Ásia e da América Latina que ainda não adquiriram riqueza econômica comparável à dos países europeus, Estados Unidos, Canadá e Japão, e nos quais a transformação científica e tecnológica da sociedade tradicional ainda não foi tão disseminada. Não quero dizer que os países de terceiro mundo sejam neutros politicamente ou que nunca tehnam formado um terceiro núcleo de poder político.
} 
geógrafos e biólogos com interesses ecológicos, têm que lidar com essa realidade; mas por que filósofos? De fato, só uma minoria de filósofos contemporâneos lida com esse problema; os outros preferem elaborar teorias sutis que parecem contribuir pouco para uma compreensão do mundo no qual estamos vivendo. É claro, essa reclamação não é um argumento; poderia ser o destino da filosofia se tornar cada vez menos relevante para o mundo moderno, um mundo muito mais intricado do que todas as culturas passadas.

Em um certo sentido, no entanto, só o fato de que podemos nos dirigir à primeira questão responde ao segundo problema. A clarificação de conceitos é uma tarefa filosófica clássica; ao pronunciar o termo "terceiro mundo", pressupomos um número de coisas altamente questionáveis, deixando-nos desconfortáveis, e essa, e esse desconforto só pode ser respondido com filosofia. Desde Platão, a filosofia foi entendida várias vezes como a metaciência universal, como a disciplina que lida com os conceitos gerais e pressuposições a partir das quais as ciências particulares começam - geralmente sem uma reflexão sobre sua validade; todavia, estou firmemente convicto de que o progresso das ciências e das humanidades nunca tornará a filosofia supérflua. Pelo contrário: a obliteração das fronteiras entre as ciências diferentes deverá deixar a filosofia ainda mais necessária; nós reconhecemos mais e mais que, no intuito de nos dirigirmos à uma questão como o terceiro mundo de forma apropriada, diferentes disciplinas têm que cooperar, e embora ainda tenhamos falta de uma teoria da ciência que tematize o trabalho interdisciplinar, a filosofia, entendida como a ciência dos princípios das diferentes ciências, pode muito bem desenvolver tal teoria. A importância da filosofia é especialmente óbvia se nós refletirmos nos pressupostos normativos das ciências e das humanidades; proposições normativas são, de fato, nem analíticas e tampouco empíricas, e portanto só a filosofia pode esperar lidar com elas de forma racional". Nós já vimos acima que, no termo "terceiro mundo", nuances avaliativas ocultas estão presentes; e precisamos de filosofia ainda mais se quisermos responder, de forma explícita, à questão normativa do que deveria ser feito face ao problema ético e político que o terceiro mundo representa. Pois é claro que a distância crescente entre o primeiro e o terceiro mundos levanta algumas das questões morais mais difíceis do mundo moderno. Não apenas traz à baila as idéias mais elementares de justiça; junto à crise ecológica ${ }^{5}$ e ao acúmulo de armas de extinção em

\footnotetext{
${ }^{4}$ Uma tese recorrente nos textos de Vittorio Hösle é a noção kantiana de que proposições normativas só podem ser proposições sintéticas a priori. Conferir, por exemplo, o artigo de HÖSLE, Vittorio. "Grandeza e limites da filosofia prática de Kant”. Veritas: Porto Alegre, v. 48 n. 1, 2003, p. 99-119. (Trad. Luís M. Sander) (N. do T.).

5 O livro mais importante sobre o assunto é o de $\mathrm{H}$. Jonas, The Imperative of Responsibility: In search of an Ethics for the Technological Age (Chicago, 1984). Eu
} 
massa, ameaça a sobrevivência da humanidade. Quase todas as questões tradicionais que dizem respeito a nosso comportamento moral parecem estranhamente obsoletas em relação a esses três problemas - pois se não obtivermos sucesso em resolvê-los, gerações futuras dificilmente terão problemas morais para se preocupar. $\mathrm{O}$ fato de que nós não tivemos sucesso em integrar - num sistema de novas normas que dizem respeito à tecnologia e ao comportamento - novas normas que digam respeito à ecologia e ao terceiro mundo, não apenas depõe contra a adaptabilidade das sociedades ocidentais; depõe também - pelo menos em certo grau, contra o sistema de pesquisa em nossas universidades, no qual nós ainda não dirigimos nossas novas tarefas de forma convincente em nossa convicção moral.

No que segue, tentarei, primeiramente, analisar a gênese histórica do problema do terceiro mundo, pois me parece que, sem reflexões em filosofia da história, a maioria das investigações morais e políticas permanecem abstratas e, freqüentemente, infrutíferas. Devemos saber a essência teórica de problemas aos quais nos dirigimos sob um ponto de vista ético; e a essência das culturas não pode ser apreendida sem conhecimento de sua história. Essa abordagem histórica, no caso do terceiro mundo, tem a vantagem adicional de que, já no século XVI, um nível teórico impressionante em relação a problemas normativos relevantes já havia sido atingido: lendo os grandes textos de Vitoria e Las Casas, achamos argumentos que nos auxiliam com problemas atuais. Em segundo lugar, tentarei discutir as questões morais distintas que nossa relação com o terceiro mundo implica; eu me focarei em aspectos econômicos, morais, políticos, e culturais. Todavia, não serei capaz de dar quaisquer respostas definitivas; eu devo estar feliz de perguntar algumas questões precisas.

\section{Assincronia na história humana}

A situação representada pela oposição entre os chamados primeiro e terceiro mundos não parece nada nova, à primeira vista, na história mundial. Pelo menos desde que há formação de culturas elevadas - a qual não ocorreu simultaneamente ao redor do mundo -, podemos falar da "assincronia" no mundo humano: há algumas culturas que são mais "desenvolvidas" que outras, e é esse diferente grau de desenvolvimento que é a razão principal para as enormes dificuldades éticas envolvidas nas relações entre eles. Quero insistir no fato de que essa assincronia é uma característica quase necessária da história humana; pelo menos é muito mais provável que culturas diferentes em regiões diferentes se desenvolvam com velocidades distintas do que se tivessem se desenvolvido simultaneamente.

mesmo lidei com essa questão na obra Philosophie der ökologischen Krise (Munique, 1991).

Vittorio Hösle - O terceiro mundo como um problema filosófico. Tradução por Gabriel Almeida Assumpção 
Assincronia, portanto, não é nada acidental, mas pertence à condição humana.

Usando o termo "mais desenvolvida" eu não sugiro que esse desenvolvimento seja necessariamente bom, que conduz necessariamente a uma forma mais elevada de ser: Essa questão, muito difícil, só pode ser endereçada depois ${ }^{6}$. Eu quero simplesmente dizer que as culturas mudam, e que há leis de mudança: certos estágios vêm, necessariamente, após outros. O novo estágio de uma cultura é caracterizado por alguns fatores que não existiam antes e que constituem um passo além no processo de racionalização ${ }^{7}$ - seja qual for a avaliação desse processo.

Embora possamos falar de racionalização em relação a vários subsistemas culturais, acho muito útil se restringirmos nossas distinções à dicotomia básica entre racionalidade técnica (instrumental) e axiológica. A primeira racionalidade visa a encontrar caminhos para a realização de seus fins, seja qual for sua natureza; culmina no poder incrível sobre a natureza e a sociedade que a ciência e a tecnologia modernas (incluindo tecnologias sociais) conferem à humanidade. $\mathrm{O}$ segundo tipo de racionalidade tenta encontrar os critérios para justificar nossos fins; e eu pressuponho aqui (novamente, sem avaliação prévia desse desenvolvimento) que a história da consciência moral da humanidade é caracterizada pelo progresso em direção a ideais universais, como elas aparecem primeiramente na religiões monoteístas e adquirem sua realização filosófica durante o Iluminismo europeu. A realização política desses ideais pressupõe também, é claro, a racionalidade técnica; a diferença entre as duas formas, portanto, não é absoluta. Todavia, a distinção entre as duas é extremamente útil.

O "progresso" em relação à racionalidade técnica geralmente (embora não sempre, e nunca imediatamente) garante à cultura mais desenvolvida um poder maior sobre as menos desenvolvidas - ou suas estruturas políticas são melhor organizadas, sua economia funciona mais eficientemente, ou novos insights na ciência permitem uma tecnologia militar melhor. O progresso em relação à racionalidade axiológica conduz a um sentimento de superioridade moral e, freqüentemente, também intelectual a qual, aos olhos da cultura superior, legimita uma assimetria em sua relação com os países menos desenvolvidos; lembro apenas da atitude dos hebreus em relação às nações politeístas que os cercavam e da divisão dos gregos entre eles mesmos e os bárbaros. O progresso tecnológico, por outro lado, geralmente não conduz a um sentimento comparável de

\footnotetext{
${ }^{6}$ Concordo com Max Weber que as ciências sociais, enquanto tais, devem ser livres de valores; ver seu ensaio "Der Sinn der 'Wertfreiheit' der soziologischen und ökonomischen Wissenschaften”, em Gesammelte Aufsätze zur Wissenschaftslehre (Tübingen, 1973), 489540. Mais isso não implica que a filosofia não possa argumentar racionalmente pelos valores.

${ }^{7}$ Sobre o conceito de racionalização, ver M. Weber, Economy and Society: an Outline of Interpretive Sociology (New York, 1968).
} 
superioridade; pelo menos mal pode justificar tal sentimento. Não é, todavia, excluído - é até natural - que uma sociedade que seja superior apenas no nível técnico tente, desesperadamente, ver-se como superior também no nível moral para legitimar seu uso do poder.

A cultura tecnicamente superior pode ou não usar essa posição vantajosa para subjugar outras culturas; pode se limitar à auto-defesa, ou pode tentar expandir seu influência por meios culturais, econômicos e/ou econômicos. A cultura que é avançada em relação à racionalidade axiológica pode desejar fazer o mesmo (mas isso não é necessário); é, no entanto, óbvio que se a sua superioridade é baseada na racionalidade axiológica, não será capaz de expandir. Até o século IV a.C., os Gregos (os quais certamente significam um novo passo no desenvolvimento da racionalidade científica e moral) não tiveram nem a ambição, nem tampouco a possibilidade de subjugar outras nações, mas quiseram apenas preservar sua independência em relação aos persas; e se abstrairmos da fundação de colônias em áreas que não eram previamente assentadas, uma expansão da cultura helênica começou somente após os próprios gregos terem sido subjugados por uma nação que eles sempre tomaram como culturalmente inferior: os macedônios. Com Alexandre o Grande, o primeiro imperialista europeu, deu-se a primeira tentativa de se impor cultura ocidental sobre nações não-ocidentais (muito antigas e complexas) ${ }^{8}$; é com sua grande expedição que surgem, pela primeira vez, as questões morais e políticas as quais têm ligação com os tópicos deste ensaio. Provavelmente, não é exagero dizer que o fracasso de seu plano não tem ligação somente com sua morte precoce, mas também com o fato de que os gregos não estavam, ainda, emocionalmente e intelectualmente preparados para lidar com essas questões. A resistência às tentativas, da parte de Alexandre, de mesclar gregos e orientais e à aceitação de alguns aspectos do estilo oriental era enorme ${ }^{9}$. Sua expedição, todavia, também promoveu o desenvolvimento de certas ideias intelectuais que contribuiram para a solução dos problemas criados pelo choque entre culturas: No Helenismo, a ética da pólis, tão característica de Platão e de Aristóteles, é cada vez mais substituída por uma filosofia moral universalista; a ideia de cosmopolitismo surge.

A próximo grande passo na história do imperialismo europeu é representado pelo Império Romano. Memorável, aqui, é o fato de que os romanos não subjugaram apenas culturas que eram menos desenvolvidas em relação a ambos conceitos de racionalidade; eles subjugaram também os gregos, cuja inferioridade em assuntos políticos e militares era compensada

\footnotetext{
${ }^{8}$ Ver o trabalho clássico de P. Jouget, Alexander the Great and the Hellenistic World: Macedonian Imperialism and the Hellenization of the East (Chicago, 1985).

${ }^{9}$ Ainda na Eneida de Virgílio, a guerra entre Otaviano e Antôno é vista como um choque entre a cultura ocidental, superior, e a cultura oriental, inferior (VIII, 671 ss.) Lembro o leitor também do Antônio e Cleopatra de Shakespeare.
} 
por sua superioridade nas artes e na filosofia. As relações peculiares que resultaram dessas assimetrias seriam dignas de um estudo independente; para meu propósito, basta lembrar que uma das razões da grandeza dos romanos consistia precisamente no fato de que reconheceram a superioridade parcial dos gregos e tentaram aprender o máximo possível deles: num certo sentido, houve uma revanche grega contra os romanos ${ }^{10}$. Em relação às culturas menos desenvolvidas subjugadas pelos romanos, dois aspectos eram especialmente relevantes: os romanos os integraram muito bem em seu próprio sistema político garantindo-lhes direitos diferentes, administrando-os de modo razoavelmente justo, e respeitando seus costumes; eles também fortaleciam o interesse dos dominados em se tornar ou em parmanecer membros do Império Romano ao acostumá-los aos aspectos confortáveis do estilo de vida romano.

Por outro lado, sabe-se bem que os bárbaros finalmente prevaleceram sobre os romanos; a partir do século III, vários imperadores romanos eram nativos de culturas menos desenvolvidas, e no século $\mathrm{V}$, o Império Romano Ocidental sucumbiu aos germanos. A partir do Império tardio até o presente os grandes historiadores, filósofos e teólogos lidaram com as causas empíricas e com o sentido mais profundo desse caso quase único na história mundial, a queda de uma grande cultura por causa de nações menos desenvolvidas políticamente, juridicamente, artisticamente ${ }^{11}$.

Como os elementos centrais das civilizações grega e romana foram internalizados pelos celtas e pelos germanos, aquela cultura que se moldou a partir disso forma a base, hoje, do primeiro mundo. Certamente, a amalgamação de romanos e germanos foi facilitada pelo fato de que o sistema de legitimidade central da nova cultura foi uma religião a qual, de um lado, era mais universalista que a precedente, e de outro, apelava para as necessidades míticas dos antigos bárbaros ${ }^{12}$. Apesar de todas as mudanças desde os primordios da Idade Média até agora, nenhum evento singular destruiu a cultura européia de forma comparável ao fim da cultura grega ou romana; a transformação estrutural da cultura européia é devida a mudanças internas e a sua expansão para outras partes do mundo. Através da última, o destino da Europa passou a ser o destino do mundo; e o terceiro mundo é o último resultado desses dois fatores: a expansão européia e o enorme

\footnotetext{
${ }^{10}$ Lembrem-se do famoso verso de Horacio: "Graecia captat ferum victorem cepit et artes / Intulit agresti Latio" (Epist. II, 1, 156s.).

${ }^{11}$ Ver D. Dermandt, Der Fall Roms: die Aufloesung des roemischen Reiches im Urteil der Nachwelt (Munich, 1984).

12 Estou convencido de que, também hoje, a religião tem uma importância insubstituível como ponte entre o primeiro e o terceiro mundo. A teologia da libertação é, sem dúvida, um dos desenvolvimentos mais positivos da América Latina. Ver G. Gutierrez, A Theology of Liberation: History, Politics and Salvation (Maryknoll, 1973); E. D. Dussel, Ethics and the Theology of Liberation (Maryknoll, 1978).
} 
progresso que a Europa moderna fez em relação aos dois conceitos de racionalidade.

Num certo sentido, pode-se dizer que algo análogo ao nosso problema atual do terceiro mundo começa com a descoberta da América. A partir do século $\mathrm{XV}$, nações européias diferentes começam a ocupar outros continentes - África, as duas Américas, Ásia, e finalmente a Austrália. Seria unilateral considerar o problema perenial Malthusiano o principal catalisador dessa colonização; as pessoas também passavam fome na Idade Média, e ninguém pensava em abandonar a Europa. Uma mudança de mentalidade era necessária para se deixar os pilares de Hércules para trás ${ }^{13}$; e não é exagero se associarmos essa mudança com a destruição do cosmos finito aristotélico, o qual caracteriza a transição da Idade Média para a Modernidade $^{14}$. A negação de qualquer fronteira dada é um dos fatores principais do mundo moderno; e é difícil para nós não admirar a curiosidade intelectual, a crença absoluta na ideia teórica, e a força de vontade que animava a empreitada de Colombo. É claro, por trás da colonização da América houve fortes interesses econômicos; o desenvolvimento rápido do capitalismo mercantil foi certamente promovido pela descoberta do ouro ${ }^{15}$.

Além da curiosidade intelectual e da pura ganância, o desejo de converter os nativos ao Cristianismo exerceu um papel; o impulso missionário desdobrou-se do caráter universalista do Cristianismo. Pode-se apreender que um fator importante nas relações entre o primeiro e o terceiro mundo desde o século XV até o presente, caso se reconheça a mistura peculiar de exploração brutal junto com o desejo sincero de ajudar os nativos, que é característica dessas relações. De fato, a relação da Espanha com as colônias americanas no século XVI permanence chocante, tanto pelas atrocidades indizíveis cometidas contra os nativos e a busca por critérios de justiça que governariam o comportamento em relação aos índios ${ }^{16}$. O leitor da Brevissima relación ${ }^{17}$ de Bartolomeu de las Casas não

\footnotetext{
${ }^{13}$ Comparar com a famosa descrição, por Dante, de Ulisses no Inferno, XXVI, 90ss.

${ }^{14}$ É memorável que mesmo em Os Lusíadas, um épico dedicado ao elogio das descobertas e das conquistas portuguesas, Camões vocifera, em certo momento, uma condenação afiada à empreitada de Vasco da Gama.

${ }^{15}$ Ver, por ex., J. H. Elliot, The Old World and the New 1492-1650 (Cambridge, 1970), 54 ss.

${ }^{16}$ Ver o trabalho clássico de L. Hanke, The Spanish Struggle for Justice in the Conquest of America(Philadephia, 1949). Fontes das relações entre Indígenas e espanhóis - como as Leis dos Burgos (1512), o Requirement (1513 - conferir) e as Novas Leis (1542) - podem ser encontradas em L. Hanke, ed. History of Latin American Civilization: Sources and Interpretations, 2 vols. (Boston, 1973), 1:87ss. É significativo que Alonso de Ercilla começe a última canção de seu famoso épico La Araucana com reflexões sobre a diferença entre guerras justas e injustas.

${ }^{17}$ Embora muitos dos numeros que Las Casas comunique não sejam corretos, a maioria dos crimes que descreve provavelmente ocorreram. A Leyenda negra era, infelizmente, realidade.
}

Vittorio Hösle - O terceiro mundo como um problema filosófico. Tradução por Gabriel Almeida Assumpção 
deve deixar o livro sem refletir no fato de que todos esses crimes puderam ser ao menos denunciados e que um público na Espanha foi tocado pelo que estava ocorrendo há milhares de milhas de distância e lutava sinceramente pela justiça. Certamente, não é fácil responder à questão: não teriam sido os padres que acompanharam os conquistadores também responsáveis, mesmo que tenham condenado a violência cometida, na medida em que sua presença, em certo sentido, legitimava a empreitada? É impossível negar que, com sua mera presença, eles contribuíram para o Cristianismo aparecer como uma religião extremamente hipócrita, a qual falava de amor universal e, todavia, era religião de criminosos brutais. Todavia, é claro que, sem a presença dos missionários, ainda mais crueldades teriam sido cometidas. A Hipocrisia pelo menos reconhece, na teoria, certas normas, e ao fazê-lo, dá aos oprimidos a possibilidade de exigir certos direitos. A brutalidade aberta pode ser mais sincera, mas sinceridade não é o único valor. A brutalidade sincera não gera nada positivo; a hipocrisia, do outro lado, traz em si a força que pode superá-la.

A descoberta do Novo Mundo mudou a vida dos nativos de forma terrível: as grandes culturas mesoamericanas e andinas ${ }^{18}$ desapareceram, milhões de pessoas morreram - parte intencionalmente, parte através de doenças importadas pelos europeus. Quase tão terrível quanto as feridas infligidas a seus corpos foi a crise de identidade na qual se emergiram os nativos $^{19}$ : eles pertenciam não mais à sua antiga cultura, e tampouco à européia. Assincronia se tornou a marca, não apenas da relação entre duas culturas diferentes, mas também de sua própria cultura, a qual não se desenvolveria organicamente mais. Assincronia intrínseca é, de fato, a caracterísitica mais marcante das culturas do terceiro mundo ${ }^{20}$.

A mente européia também foi tranformada pelo encontro ${ }^{21}$. A descoberta de outras culturas e de um novo mundo aumentou o horizonte e mostrou novas possibilidades intelectuais. Todavia, contribuiu para a crise da crença dos europeus em sua própria cultura; e essa crise só foi reforçada pelos crimes cometidos pelos europeus. Muitos trabalhos da literatura posterior sobre o colonialismo - eu lembro especialmente do Heart of Darkness de Joseph Conrad - descrevem, com horror, o barbarismo no qual os europeus caíram; e todos eles pressupõem, corretamente, que a repetição

\footnotetext{
${ }^{18}$ Ver, sobre essas culturas, G.A. Collier et al., eds., The Inca and Aztec States 1400-1800: Anthropology and History (New York, 1982).

19 Comparar com N. Wachtel, The Vision of the Vanquished: The Spanish Conquest of Peru through Indian Eyes 1530-1570 (Hassocks, 1977).

20 No libretto de G. Giacosa e L. Illica para a Madame Buterfly de Puccini, a situação terrível resultante de não mais pertencer nem ao à cultura antiga, tampouco à nova, é descrita eloquentemente.

21 Isso é muito bem mostrado em T. Todorov, The Conquest of America: The Question of the Other (New York, 1984). O livro é extremamente importante porque encontra uma lógica na história da abordagem européia do novo mundo. Eu devo muito a ele.
} 
dos mesmos rituais cruéis dos nativos, da parte dos europeus, é algo moralmente muito mais ultrajante do que os feitos originais dos bárbaros. Pois regressão é sempre pior do que falta de desenvolvimento. Nesse contexto, é memorável que, já no século XVI, a idealização do nobre selvagem se inicia. A nostalgia pela mente arcaica e o nojo do barbarismo retroativo andam de mãos dadas, e só quando, nos últimos dois séculos, a subjetividade perdeu todo o contato com uma ordem de valores objetivos, a idealização se tornou dominante.

Desse confronto entre europeus e nativos-americanos, já no século XVI, duas disciplinas importantes se desenvolveram: o direito internacional e a antropologia. As Relectio de iure belli, de Francisco de Vitória, a primeira tentativa para se encontrar critérios legais para guerras justas, foram, como ele diz no prefácio, motivadas pela conquista da América ${ }^{22}$; e quem quer que estude suas Relectio de Indis permanece boquiaberto com em nível de argumentação do livro. Vitória dispensa as tentativas de justificatição da conquista que não tenham sentido moral e reconhece aqueles títulos legais que, até hoje, são aceitos como justos. É especialmente digno de observação que o frei dominicano desaprove a idéia de que a rejeição da fé cristã pudesse legitimar uma guerra justa contra os indígenas (II 4); ele acredita, todavia, que uma recusa em ouvir aos missionários cristãos pudesse justificar uma guerra (III 2).

Mas, novamente, ele repete que a situação legal entre os espanhóis e indígenas deve ser simétrica; para qualquer direito válido para os espanhóis, deve haver um direito válido para os indígenas (II 3). Vemos aqui, as idéias universalistas do direito natural cristão aplicadas às relações interculturais e internacionais; e, de fato, o desenvolvimento posterior da filosofia do direito na Era do Iluminismo continua essas linhas argumentativas, os últimos resultados das quais são a ética universalista de Kant e o estado constitucional moderno. "Todos os homens são seres racionais" e "os índios não são escravos por natureza" serão duas das formulações mais significativas de Las Casas em sua disputa com Ginesius de Sepulveda, que usou a doutrina de Aristóteles da escravidão natural com intuito de legitimar o comportamento espanhol contra os índios ${ }^{23}$.

Mas a aplicação de idéias universalistas a culturas estrangeiras não é a única grande descoberta do século XVI. A segunda descoberta importante é, como eu já disse, a antropologia. Enquanto as culturas não-cristãs conhecidas à europa medieval eram baseadas em duas outras religiões monoteístas e partilhavam, portanto, muitos padrões de racionalidade com

\footnotetext{
${ }^{22}$ As preleções de Vitória são acessíveis numa tradução francesa com uma introdução excelente por M. Barbier na seguinte edição: F. De Vitória, Leçons sur les Indiens et sur le droit de guerre (Geneva, 1966).

${ }^{23}$ Ver, sobre sua famosa disputa, L. Hanke, All Mankind Is One:A Study of the Disputation Between Bartolomé de Las Casas and Juan Gines de Sepulveda in 1550 on the Intellectual and Religious Capacity of the American Indians (De Kalb, 1974).
} 
os cristãos, o fato mais desconcertante sobre os indígenas era sua alteridade. É de extrema importância perceber que a urgência de diferenciação dos índios no contexto do século XVI era um topos dos conservadores; pois se os índios não fossem como os europeus, por que a eles os mesmos direitos deveriam ser concedidos? O interesse antropológico em diferenças entre culturas parecia contradizer o pathos universalista de uma identidade fundamental de todos os seres humanos no que diz respeito aos direitos básicos. É essa tensão - entre a descrição sem vieses da alteridade e a idéia normativa de igualdade - que constitui, até hoje, o problema principal em qualquer teoria de relações justas entre as culturas diferentes; e eu acredito que ainda estejamos longe duma teoria satisfatória.

Todavia, a situação não é simplesmente tal que o interesse na alteridade é necessariamente ligado ao desrespeito aos direitos de outra culutra. Deixe-me lembrar de um problema no qual os espanhóis estiveram profundamente engajados - tenho em mente, é claro, os sacrifícios humanos. Há pouca dúvida de que os conquistadores espanhóis (certamente, pessoas acostumadas com o derramamento de sangue) estavam sinceramente chocados com os sacrifícios ${ }^{24}$; eles freqüentemente legitimavam sua brutalidade com essa instituição. Aqui, de forma curiosa, as idéias universais - as quais incluem respeito pela vida humana inocente foram usadas como um pretexto para agir contra os indígenas de forma incompatível com tais idéias. Até Vitoria aceita como um título legítimo de conquista a preocupação com vidas inocentes que seriam,de outra forma, sacrificadas (também no caso em que as vítimas concordam em ser sacrificadas: III 5). (Las Casas, todavia, insiste que esse título se tornaria inválido se levasse a uma guerra na qual mais pessoas fossem mortas do que se fosse, de fato, salvas dos sacrifícios). Agora, é difícil negar a plausibilidade do argumento de Vitória. Caso se aceite, com base em uma ética universalista, os direitos fundamentais dos índios, dificilmente pode-se negar esses direitos as suas vítimas; desse modo, as idéias universalistas as quais, por si pareciam proteger os indígenas, parecia também legitimar, pelo menos enquanto ultima ratio, as interferências violentas em sua cultura.

É nesse contexto que Las Casas tenta, pela primeira vez na história do mundo, desenvolver um entendimento histórico imanente de uma cultura menos desenvolvida. Primeiro, ele lembra seus contemporâneos de que as nações européias, em seu passado, também cometeram sacrifícios - Abraão esteve disposto a matar seu próprio filho. Em segundo lugar, ele vê um sentido moral profundo em sacrifícios humanos: os índios querem sacrificar para Deus o bem mais precioso que conhecem, e este é a vida humana. O que parecia ser um sinal de grande desrespeito pela vida humana resulta, na

\footnotetext{
${ }^{24}$ Ver B. Diaz del Castillo, Historia verdadera de la conquista de la Nueva España, ed. R. Leon-Portilla, 2 vols. (Madrid, 1984), 1:344ss.
} 
verdade, da maior elevação possível ${ }^{25}$. É claro que Las Casas é convicto de que, a longo prazo, sacrifícios humanos têm que ser abolidos; mas a avaliação desse costume, no contexto da cultura deles, o permite ver como é menos repelente do que parecia a todos os seus contemporâneos europeus ${ }^{26}$.

Parece-me que uma das razões para a grandeza teórica (e não apenas política) de Las Casas é que, em sua abordagem da cultura indígena, interesses antropológicos etnográficos estão ligados a um pathos universalista em relação aos direitos humanos fundamentais. Poucos depois dele foram capazes de combinar as duas abordagens: Kant e Mill de um lado desenvolveram, duas variantes diferentes de ética universalista; mas nenhum deles lida com o fato de que a ética universal, por si só, é um resultado de um longo processo histórico. Kant acredita que o imperativo categórico é atemporal, não apenas no que diz respeito a sua validade, mas também em relação ao seu reconhecimento pelos humanos; portanto ele não pode nem por em questão (muito menos respondê-la) como devemos agir em relação a culturas às quais nossos princípios universalistas ainda são alheios. O problema ético principal da ética kantiana é que ela pressupõe simetria: nãohumanos, portanto, podem ser seus sujeitos tão pouco quanto culturas com uma mentalidade que não é ainda comparável com nossos ideais universalistas. Seu universalismo, o qual ignora a história da consciência moral, de fato não pode ser a base de uma teoria normativa apropriada das relações interculturais.

De outro lado, a preocupação crescente com a alteridade e com a diferença na antropologia moderna parece solapar a possibilidade de proposições normativas, e mesmo de conhecimento teórico. Deve haver um elemento comum com intuito de abordar outra cultura. Se não houvesse identidade, eu não poderia nem indicar as diferenças, mas teria que manter silêncio em relação à outra cultura; não seria possível dizer que a análise moderna da racionalidade arcaica signifique um progresso em relação ao ponto de vista a-histórico do iluminismo ${ }^{27}$. Ainda mais perigosa é a confusão de nossos pós-modernos entre gênese e validade. Se, do fato de que a idéia de direitos humanos é um produto da história, seguisse que não

25 Ibid., 221ss., esp. 234. Todorov vê, corretamente, na atitude de Las Casas, um novo passo no reconhecimento da alteridade (Conquest of America, 186ss.).

${ }^{26}$ Em alguns aspectos, a abordagem de Las Casas traz à mente a teoria de Max Scheler de que nenhuma cultura conseguiu justificar o assassinato - o aassassinato de escravos, por exemplo, não era considerado assassinato, pois os escravos não eram considerados pessoas. O que parece um desvio em relação a princípios morais básicos é, do ponto de vista dele, um erro de incorporação de algo numa categoria mais geral. Ver Formalism in Ethics and Non-Formal Ethics of Values (Evanston, 1973), 309ss.

27 A teoria wittgensteiniana de jogos de linguagem foi aplicada por P. Winch à teoria das culturas:The Idea of a Social Science and Its Relation to Philosophy (London and New York, 1958). Para uma crítica de sua abordagem, ver meu ensaio „Eine unsittliche Sittlichkeit. Hegels Kritik and der indischen Kultur”, em W. Kuhlmann, Ed. Moralität und Sittlichkeit (Frankfurt, 1986), p. 136-82. 
possui validade intercultural, então, certamente, qualquer tentativa de encontrar critérios de justiça nas relações entre primeiro e terceiro mundo seria fútil; pois a idéia de justiça não se aplicaria a relações interculturais.

Parece, portanto, óbvio para mim que apenas insights universalistas baseados na tradição do direito natural combinada com uma consciência historicista podem nos ajudar a endereçar nosso problema. $\mathrm{O}$ primeiro pensador europeu que elaborou uma filosofia normativa da cultura humana que conseguiu os dois foi $\mathrm{Vico}^{28}$; e nas últimas décadas é especialmente o trabalho de Kohlberg na ontogênese da consciência moral que nos deu uma base sólida para a realização desse programa. A aplicação dos estudos de Kohlberg da reconstrução da filogênese da consciência moral por Apel e Habermas é, a meus olhos, a abordagem mais promissória do problema de relações interculturais. Como se sabe, Kohlberg, Apel e Habermas distinguem seis tipos diferentes de consciência moral, a última das quais é caracterizada por ideais universalistas ${ }^{29}$. Eu acredito, todavia ${ }^{30}$, que um sétimo passo deve ser adicionado: um passo no qual a mente universalista reconhece que sua posição é a maior, mas também a última, e que portanto tem que conviver dcom culturas as quais ainda não a atingiram. Mesmo os maiores iluministas não superaram o sexto estágio: isso parece ser o limite mais doloroso da consciência burguesa moderna.

O que dissemos até agora é necessário, mas ainda não suficiente para entender a essência do terceiro mundo. A consquista da América foi apenas o primeiro passo na gênese do terceiro mundo. Um salto qualitativo nas relações entre culturas européias e não-européias aconteceu com a revolução industrial; e as diferenças entre a colonização da América no século XVI e a da África negra no fim do século XIX se devem, principalmente, à profunda mudança a qual, enquanto isso, tomou lugar na tecnologia e na consciência da Europa. O último passo foi a descolonização ${ }^{31}$.

${ }^{28}$ Sobre Vico e sua atualidade, ver meu ensaio introdutório "Vico und die Idee der Kulturwissenschaft", em G. Vico, Prinzipen einer neuen Wissenschaft über die gemeinsame Natur der Völker, 2 vols. (Hamburg, 1990). (Ver também , Natur und Wissenchaft in Vicos neuer Wissenschaft vom Geist" na obra de Hösle, Philosophiegeschichte und objektiver Idealismus, (München: Beck, 1996), p. 153-179 (N. do T.) )

29 L. Kohlberg, Moral Stages: A Current Formulation and a Response to Critics (Basel, 1983); J. Habermas, Moralbewusstsein und kommunikatives Handeln (Frankfurt, 1983); K.O. Apel, Diskurs und Veranwortung (Frankfurt, 1988)

${ }^{30}$ Na verdade Kohlberg, Habermas, e Apel discutiram se há um sétimo passo; mas eles têm em mente algo mito diferente do que eu. Veja o ensaio de Apel "Die transzendentalpragmatische Begründung der Kommunikationsethik und das Problem der höchsten Stufe einer Entwicklungslogik des moralischen Bewusstseins”, em Diskurs und Verwantwortung, 306-69.

${ }^{31}$ Sobre as "três fases de dependência", ver S. C. Toton, World Hunger: The Responsibility of Christian Education (Maryknoll, 1982), 2ss. (com referência a Th. dos Santos). Sobre o 
As mundanças principais que ocorreram na Europa após a descoberta da América foram passos adiante no processo de racionalização, o qual conduziu à nova ideia de ciência, muito diferente daquela dos gregos, a qual se aliou ao programa tecnológico e a uma nova forma de economia, o capitalismo $^{32}$. A unidade da cultura medieval se dividiu; subsistemas culturais diferentes como amor, economia, política, a arte militar, e a religião se tornaram autônomos ${ }^{33}$; a racionalidade técnica se desenvolveu a um ponto nunca antes visto na história humana. A Revolução Industrial deu às culturas de pano de fundo europeu uma liderança a qual tem sido muito, muito difícil alcançar; seu poder superior foi consolidado por séculos; a assincronia do mundo foi moldada de forma única na história do mundo. Isso é ainda mais válido quando se considera que o triunfo da tecnologia moderna enraiza-se numa mudança radical de mentalidade e que, provavelmente, mudou a alma humana como nenhuma outra desde o Neolítico. Isso, a propósito, facilmente explica as dificuldades de transferência de tecnologia: culturas que não passaram por essa mudança de mentalidade são muito propensas a falhar, caso adotem tecnologias ocidentais (a maior exceção a essa regra, o Japão, é extremamente difícil de se entender).

Simultaneamente ao desenvolvimento do novo programa cientifico, progresso importante ocorreu no âmbito dos ideais universalistas; baseados na outra grande descoberta da modernidade - a subjetividade soberana sistemas politicos que garantissem o direito de auto-determinacao do indivíduo foram criados em grau único na história mundial. A essência dos Estados Unidos da América é ter conseguido desenvolver essas duas ideias da modernidade de forma muito mais pura do que os europeus; situados num novo continente, pode, pelo menos parcialmente, abstrair de toda a história passada. A autonomia da tecnologia levou a um abismo crescente entre racionalidade técnica e axiológica, um abismo extremamente perigoso para a estabilidade intelectual e moral da Europa. O processo de racionalização se tornou mais e mais vazio; a capacidade de identificação emocional com uma comunidade - uma condição necessária para a felicidade - decaiu rapidamente; e as forças centrífugas do individualismo extremo ameaçam crescentemente a crença do racionalismo tradicional no mundo enquanto uma ordem estruturada. Desde que o sacrifício e a renúncia não mais parecem necessários para a maioria de nós, a vontade de se sacrificar, ou pelo menos de renunciar, desaparece.

colonialismo e a descolonização, ver, p. ex., St. C. Easton, The Rise and Fall of Western Colonialismo (New York e London, 1964) e R. F. Holland, European Decolonization 19181981: An Introductory Survey (Hamburg, 1957).

${ }^{32}$ Ver A. Gehlen, Die Seele im teschnischen Zeitalter (Hamburg, 1957).

${ }^{33}$ Comparar com H. Broch, Die Schlafwandler (Zürich, 1952), 525ss. 
O elo entre o novo sistema político e a nova tecnologia é fornecido pelo capitalismo. Nenhum outro sistema econômico teve a dinâmica de produzir tantas mercadorias e garantir tanta autodeterminação individual; promovido pela evolução da ciência e tecnologia, através das quais acelerou fortemente seu desenvolvimento. As consequências negativas do capitalismo, todavia, não são menos chocantes que suas vantagens: uma acentuação - pelo menos temporária - das polarizações entre ricos e pobres, uma mudança no sistema de valores do indivíduo, e uma necessidade desesperada de recursos baratos para satisfazer as necessidades que gera. A explosão demográfica que o mundo testemunhou desde o último século começou nos países industrializados (onde, por si só, tornou-se possível). O número crescente de cidadãos, assim como ideias de distrubuição igualitária que levou a necessidades crescentes causou, inevitavelmente, dois de nossos problemas contemporâneos principais: a crise ecológica e o terceiro mundo. Colônias foram necessárias parcialmente para conseguir recursos, parcialmente para encontrar novos mercados: não se precisa ser um marxista para reconhecer a racionalidade econômica por trás da política colonial da era imperial. O imperialismo do século XIX tardio e dos primórdios do século XX se baseavam em ideias nacionalistas: uma pluralidade de estados completamente soberanos competiu pelo poder político e econômico. O caráter antiuniversalista do nacionalismo é claramente em conflito com a tendência principal do desenvolvimento moderno: as duas Guerras Mundiais foram um resultado ${ }^{34}$.

É de extrema importância ver que o colonialismo moderno foi, apesar de seu caráter antiuniversalista, um desdobramento quase necessário do individualismo moderno. As ideias ocidentais de liberdade e de justiça social levaram, paradoxalmente, à subjugação das colônias. Para garantir o crescimento econômico dentro dos estados industrializados, muitos recursos do terceiro mundo eram e são desesperadamente necessários. A luta entre as potências industrializadas foi, todavia, supérflua e, mesmo, contraproducente; e após a Segunda Guerra Mundial, uma nova ordem política foi criada, a qual, pela primeira vez na história moderna, uniu quase todos os países industriais numa estrutura política e militar. Até 1989, entretanto, os países ocidentais sofreram oposição dos países socialistas. Sua ideologia negava as ideias da base do capitalismo moderno; todavia, ela aceitou livremente a opção "industrialista" moderna por uma sociedade tecnológica.

O desenvolvimento do terceiro mundo após a Segunda Guerra Mundial caracteriza-se por três tendências. A mais importante foi, é claro, a descolonização a qual, em relação às colônias americanas - as mais antigas - começou já no final do século XVIII. A ideia européia de nacionalismo, a

\footnotetext{
${ }^{34}$ A respeito do imperialismo, ver o livro ainda importante de J. A. Hobson, Imperialism: A Study (New York: 1902).
} 
qual entrou nas mentes das elites do terceiro mundo, tornou-se uma das causas principais da batalha pela independência. Há, claramente, algo paradoxal nesse fato: a própria ideia que se provou ser a contribuição mais perigosa da Europa para a política mundial foi usada para fundar as reinvindicações das colônias pela liberdade. O leitor do famoso livro Les damnés de la terre, de Fanon, não pode evitar sentir que todas as categorias que ele usa para questionar a dominação política e cultural dos europeus sobre as colônias são resultados típicos da história intelectual européia, especialmente da ideia de nação ${ }^{35}$. A África conheceu tribos e, talvez, uma solidariedade pan-africana, mas certamente não nações no sentido europeu $^{36}$.

Em segundo lugar, a descolonização dura não terminou com a dependência. Foi meramente transformada de uma dependência constitucional em uma econômica. De um lado, isso era bem-vindo intervenções militares brutais do lado dos poderes coloniais se tornou mais raro. De outro lado, a dependência econômica, embora não tão manifesta quanto antes, piorou a situação parcialmente. Corporações multinacionais são mais anônimas e, por conseguinte, mais difíceis de se controlar do que governos. A soberania formal dos novos estados enfraqueceu o senso de responsabilidade das antigas potências coloniais; em muitos estados isso deixou a ajuda mais difícil em casos de emergência. As novas elites foram e são frequentemente extraordinariamente corruptas; elas geralmente identificam-se com o modo de vida ocidental e, para participar dele, tem que conseguir dinheiro seja por quais meios puderem. A assincronia intrínseca dos países do terceiro mundo é a razão principal para a corrupção - o fato de que eles frequentemente nem mesmo assimilaram uma moral de orientação para a Lei e para a Ordem ${ }^{37}$, mas são confrontados com as tentações da riqueza moderna. A insurgência, por mais compreensível que seja, raramente facilita a situação (pelo menos se não imediatamente com sucesso), e a instrumentalização do terceiro mundo durante a guerra fria, quando o conflito entre as duas superpotências foi lutado pelos países mais pobres dificilmente contribuiu para uma melhora nessa situação ${ }^{38}$.

${ }_{35}^{35}$ F. Fanon, The Wretched of the Earth (New York, 1968), 50.

36 Ver R. Bjornson, The African Quest for Freedom and Identity: Cameroonian Writing and the National Experience (Bloomington and Indianopolis, 1991), 3.

37 "Law-and-Order moral", no original. Provavelmente, Hösle se refere, aqui, à teoria do desenvolvimento moral de Lawrence Kohlberg, correspondente ao estágio 4, no qual ainda rege uma moral convencional, marcada pelo grande respeito à autoridade, por regras fixas e pela manutenção da ordem social. A justiça se vincula com a ordem social estabelecida, não se tratando de escolha pessoal moral. Esse estágio se mostra o mais frequente entre adultos. (Biaggio, A. M. B. Lawrence Kohlberg: Ética e Educação Moral. São Paulo: Moderna, 2006. P.26) (N. do T.).

${ }^{38}$ Apesar de sua simpatia pela violência, mesmo Fanon rejeita a Guerra Fria. "Esses engenheiros que se transformaram em técnicos de guerra nuclear, poderiam, no espaço de cinquenta anos, elevar o padrão de vida dos países subdesenvolvidos em 60 por cento. 
O terceiro aspecto do terceiro mundo no pós-guerra é a crença, amplamente espalhada, de que é meramente uma questão de tempo antes que os países em desenvolvimento alcancem o nível do primeiro - ou pelo menos do segundo - mundo. Ideias universalistas, assim como a fé reforçada pela tecnologia - segundo a qual, em princípio, tudo pode ser alcançado, levaram a essa crença. Ademais, as disparidades entre o primeiro e o terceiro mundos, neste sentido, tornam-se suportáveis; como télos do mundo, imaginou-se um estado no qual, em princípio, todas as pessoas poderiam viver uma vida comparavel àquela do primeiro mundo. Agora, essa esperança não foi cumprida, como sabemos hoje que isso não será realizado, porque não pode ser realizado. $O$ modo ocidental de vida não é universalizável - se todos os habitantes desse planeta consumissem tanta energia quanto o americano e o europeu comum, numerosos ecossistemas em nosso planeta já teriam entrado em colapso ${ }^{39}$. Mas mesmo se uma universalização fosse possível, seria o valor intrínseco do primeiro mundo, de fato, tão alto que poderíamos desejar que fosse universal? É com essa pré-história e com essas dúvidas em mente que nós agora devemos nos endereçar às questões éticas que dizem respeito às relações entre o primeiro e o terceiro mundo.

\section{Critérios morais}

Após ter descrito o curso principal dos eventos e a lógica por trás deles, tentemos avaliá-los e encontrar critérios morais para as relações entre o primeiro e o terceiro mundos. Eu começo com a afirmação de que o primeiro mundo tem uma responsabilidade de melhorar, o tanto quanto possível, a situação do terceiro mundo. Três razões se apresentam para tal responsabilidade. Primeiro, é no auto-interesse racional do Ocidente prevenir pelo menos uma polarização ainda maior dos dois mundos. É extremamente improvável que um mundo no qual menos de 10 por cento da população disponha de nada mais do que três quartos da riqueza do mundo possa ser pacífico; dificilmente pode se esperar que pessoas as quais não tenham nada a perder possam renunciar ao uso da violência, caso essas seja a única maneira de satisfazer suas necessidades básicas. Especialmente em conexão com as prováveis catástrofes ecológicas do próximo século, as migrações são muito prováveis, para as quais não estamos preparados nem política e tampouco moralmente. Em geral, é um dos maiores erros da civilização moderna querer reparar ao invés de prevenir; nossa medicina difere da dos antigos porque a nossa insiste muito mais em terapia do que

Então, vemos que os verdadeiros interesses dos países subdesenvolvidos não está nem na intensificação e nem na acentuação dessa guerra fria". (Wretched of the Earth, 82).

39 Cf. E.-U. von Weizäcker, Erdpolitik. Ökologische Realpolitik an der Schwelle zum Jahrhundert der Umwelt. (Darmstadt, 1989). 
em prevenção. Analogamente, a segurança nacional é considerada mais em termos de se vencer uma guerra do que em se prevenir dela; especialmente após o provável fim da guerra fria, é óbvio que óbvio que o conflito NorteSul é o mais perigoso no globo. O direito de auto-defesa não pode ser negado; é, todavia, claro que o uso desse direito se torna questionável ou, pelo menos, não-isento de culpa se não se tiver feito tudo o possível para evitar uma situação na qual auto-defesa se torna necessária.

A segunda razão tem a ver com a pré-história do terceiro mundo. Desde que o primeiro mundo interveio nessas culturas, destruiu seu desenvolvimento natural, forçou sobre elas uma assincronia intrínseca e desproveu dela sua unidade orgânica anterior, teve uma responsabilidade por sua situação atual que pode ser comparada com a responsabilidade civil de uma pessoa que causou dano. Tendo tomado seus recursos e muito de sua força de trabalho, contribuiu para sua própria riqueza e para a pobreza delas; é, portanto, apenas justo que devolva parte do que tirou. É claro que há numerosas objeções a esse argumento: por exemplo, prescrição é considerada um princípio importante da lei, e não é claro de modo algum a quem o dinheiro deve ser devolvido. Todavia, parece-me que o núcleo do argumento é válido pelo menos no nível moral, se não no político, e que deve entrar em nossas consciências de modo mais profundo do que fez até o presente. Isso se mostra ainda mais nítido enquanto a exploração dos recursos e da força de trabalho do terceiro mundo continua.

É, todavia, claro que não faz sentido que os países do terceiro mundo caiam em autocomiseração e reclamem sobre os crimes das potências coloniais - a autocomiseração é o maior obstáculo contra o domínio do futuro. $\mathrm{O}$ que aconteceu, aconteceu; e a maturidade consiste em fazer o melhor uso possível disto. E, de fato, não pode ser negado que a introdução forçada de certos padrões de racionalidade ocidental também deu aos países em desenvolvimento a chance de superar injustiças e calamidades prévias. O problema geral é se a concepção segundo a qual se deve tornar mais aguda a percepção, pelas pessoas, das injustiças, também não se aplica aqui: de um lado, somente assim as injustiças podem ser superadas; de outro lado, o ressentimento em relação ao passdo é uma das coisas mais inúteis do mundo. Uma mudança de consciência é a primeira condição para superar a opressão $^{40}$; a falta de realismo e ódio raramente ajudam ${ }^{41}$.

Enquanto os primeiros dois argumentos tem, primariamente, relação com a responsabilidade moral de estados e de culturas, o terceiro argumento se aplica à responsabilidade individual, não pressupõe culpa individual e

40 Ver os trabalhos de Paulo Freire, por exemplo, Education for Critical Consciousness (New York, 1973) (Edição Brasileira: FREIRE, Paulo. Educação como prática da liberdade. 20. ed. Rio de Janeiro: 1991 (N. do T.) )

41 Isso tem que ser dito contra as idéas grotescas de revolução mundial circulando no fim dos anos 60. Ver, por exemplo, o prefácio de Sartre ao livro de Fanon, o qual é cheio de erros tanto no nível descritivo quanto no normativo. 
nem coletiva. Foi afirmado pela primeira vez, até onde sei, por Albert Schweitzer, que descreveu como, quando era menino, ele percebeu subitamente como ele teve sorte de ter sido criado numa família boa. Ele sentiu que tinha que abrir mão de algo pela sua sorte; e esse sentimento foi o que levou, finalmente, para a decisão de sua vida ${ }^{42}$. Schweitzer não tentou argumentar por esse princípio; isso foi feito por outros filósofos na base dum conceito existencialista de liberdade. De acordo com eles, uma propriedade essencial de uma pessoa é adqueirida por si mesmo, e propriedades inatas podem se tornar adquiridas apenas se agirmos de forma a merecê-las. Apenas expressando solidariedade com os menos beneficiados que merecemos realmente nossa sorte e nos tornamos genuinamente livres ${ }^{43}$.

Mas porque deveriamos praticar solidariedade com os mais pobres? Nossa moralidade cotidiana é fortemente definida pro uma ideia que volta à doutrina estóica da oikeosis e encontra sua expressão também no preceito do Evangelho: ama teu próximo. De acordo com essa ideia, nossos deveres morais diminuem em proporção direta à distância física de possíveis sujeitos desses deveres. Agora, de um lado, é óbvio que seria absurdo alimentar uma pessa a milhares de milhas de distância enquanto meu irmão passa fome. De outro lado, essa regra deveria ser suplementada pelo ato de levar em consideração a intensidade dessa necessidade. Parece-me mais moral se, por exemplo, parentes se pedissem para enviar dinheiro para organizações inteligentes do terceiro mundo, ao invés de comprar uns para os outros presentes de Natal que não preenchem nenhuma necessidade genuina. Eu sei, é claro, que - embora esses princípios façam sentido completo antes da razão - é extremamente difícil considerar isso viável num nível motivacional. No passado, nenhuma cultura considerou um dever ajudar culturas distantes que estavam sofrendo de fome. O fato, todavia, de que através da mídia moderna nós temos conhecimento direto do que está ocorrendo longe muda a situação; e também a ciência de que, em princípio, através da tecnologia moderna, a fome pode ser superada aumenta nossa culpa em casos de omissão.

É, todavia, claro que a ajuda de pessoas privadas - por mais importante que seja - nunca pode ser o suficiente para resolver o problema; e, infelizmente, não pode ser negado que muitos projetos bem-intencionados

\footnotetext{
${ }^{42}$ A. Schweitzer, Aus meinen Leben und Denken (Leipzig, 1932), 70.

${ }^{43}$ H. Spigelberg, "Good Fortune Obligates: Albert Schweitzer's Second Ethical Principle", in Steppingstones Toward an Ethics for Fellow Existers: Essays 19441983(Dordrecht/Boston/Lancaster, 1986), 219-229; O. Wiggins, "Herbert Spiegelberg`s Ethics: Accident and Obligation”, Journal of the British Society for Phenomenology 21 (1990): 39-47.
} 
aumentaram a situação desesperadora do terceiro mundo ${ }^{44}$. Mudanças incisivas nos níveis econômico, político, e cultural são necessários.

Para começar com as relações econômicas entre o primeiro e o terceiro mundos, uma avaliação moral apropriada é extremamente difícil. De um lado, temos a teoria neoclássica tardia, segundo a qual cada preço que resulta de um contrato livre é, por definição, o preço certo; os preços que pagamos hoje por produtos do terceiro mundo são dessa forma, por definição, justos. Mas essa teoria - um pendante do positivismo legal - é claramente inaceitável: resolve o problema normativo apenas eliminando-o. De outro lado; nós temos a teoria marxista da exploração, e isso é igualmente inaceitável, não apenas porque sua meta - a introdução duma economia planejada - aumentaria a exploração, mas também porque a doutrina pressupõe uma teoria de valores que simplesmente não faz sentido mais, embora também o fosse a doutrina de Smith e de Ricardo. Aquilo de que nós precisaríamos para criticar, de forma profunda, as relações entre o primeiro e o terceiro mundos é uma teoria apropriada de valores; e nossa cultura não dispõe de tal teoria. Crítica de qualidade ao capitalismo é sempre importante, mas infelizmente não é fácil - o Marxismo, de qualquer modo, não pode ser sua base.

Não obstante, permitam-me nomear quatro objeções que, agora, são possíveis contra o sistema mundial atual. Nas últimas décadas, economistas argumentaram que os preços excessivamente baixos dos recursos naturais são uma das razões principais para a destruição do ambiente ${ }^{45}$. Estou convencido de que o argumento é correto e de que os custos, por exemplo, do reflorestamento deveriam incluir o preço da madeira ou os custos de plantar novas árvores (o que poderia limitar o efeito estufa) deveriam ser adicionados ao preço da gasolina. Agora, é claro que preços mais altos melhorariam as economias daqueles países que dispõem de recursos importantes; eles piorariam, todavia, as economias dos países sem tais recursos. Pode-se questionar a justiça de um mundo no qual o poder econômico dependeria - até mais do que hoje - das contigências da distrubuição de recursos importantes; mas certamente limites na pilhagem da Terra seriam, a longo termo, interesse de países que vivem de exportação dos seus recursos escassos.

A superioridade moral do capitalismo sobre o feudalismo é baseada na ideia de que todo agente é, pelo menos em princípio, igual e livre. É, todavia, que não é só o mérito que determina o poder de alguém no jogo econômico: a sorte e a herança também contribuem para as chances de

\footnotetext{
${ }^{44}$ Sobre as causas da fome mundial, ver S. George, How the Other Half Dies: The Real Reasons for World Hunger (Montclair, 1977); Toton, World Hunger; F. M. Lapṕé e J. Collins, World Hunger: Twelve Myths (New York, 1986).

${ }^{45}$ Ver, por ex., H. Bonus, Marktwirtschaftliche Konzepte im Umweltschutz (Stuttgart, 1984).
} 
alguém. Dentro da economia do mesmo país, todavia, há mecanimos redistributivos (tais como impostos) os quais, embora sempre apenas parcialmente, corrijam disparidades que se tornaram muito grosseiras. Esses mecanismos existem apenas dentro dos países desenvolvidos; não se aplicam a países de terceiro mundo e não se aplicam a relações econômicas. Destarte, o abismo entre países ricos e pobres tende a se aprofundar, se nada for feito a respeito ${ }^{46}$. Pois o princípio do contrato livre, por mais importante que seja, leva a preços justos apenas se os dois lados possuem poder contratual comparável; e é óbvio que o poder contratual de uma pessoa (ou país) que desesperadamente precisa de comida é, de longe, inferior ao duma pessoa rica, pois o pobre não pode esconder seu ou sua ordem de preferência. Quanto mais pobre se é, mais duro tem que se trabalhar para satisfazer necessidades básicas - essa idéia dificilmente poderia ser vista como um princípio justo. Eu abstraio completamente do fato de que, na maioria dos países do terceiro mundo, não existam possibilidades de organizar os trabalhadores de forma comparável à nossa. Isso contribui para o baixo preço da força de trabalho da qual não apenas a elite do terceiro mundo, mas também a do primeiro, tira vantagem.

A terceira objeção contra a justiça da situação presente resulta do trabalho pioneiro de Max Weber sobre os pressupostos intelectuais do capitalismo $^{47}$. Onde essas mudanças de mentalidade não ocorreram, o capitalismo dificilmente poderia levar à riqueza universal - isso parece ser a consequência lógica do trabalho de Weber. É claro, é fácil culpar o terceiro mundo por sua falta das virtudes secundárias clássicas do capitalismo autodisciplina, parcimônia, etc.; mas é ingênuo e a-histórico assumir que o Homo oeconomicus sempre existiu. A aparente justiça de tratar cada ser humano como tendo a mesma racionalidade econômica é, na verdade, a maior injustiça ${ }^{48}$. Certamente, é necessário que, no final das contas, o terceiro mundo internalize pelo menos o essencial da ética de trabalho capitalista (isso, a propósito, parece mais fácil em culturas asiáticas do que nas africanas); mas, enquanto ainda não é o caso, uma política de crédito como aquela dos últimos vinte anos é altamente imoral ${ }^{49}$. A corrupção das elites foi bem conhecida (e bem-vinda, pois a corruptabilidade é sempre para benefício dos mais ricos); e para cada pessoa que teve até o conhecimento mais modesto dos pressupostos culturais da tecnologia, foi óbvio que todos os projetos gigantes pelos quais se ganhou crédito foram fadados ao fracasso, deixando apenas dívidas. A importância social e política da dívida atual lembra a história antiga, com a distinção importante,

\footnotetext{
${ }^{46}$ Sobre economia do terceiro mundo, o trabalho clássico ainda é o de G. Myrdal, Asian Drama: An Inquiry into the Poverty of Nations. (New York, 1972).

${ }^{47}$ M. Weber, The Protestant Ethic and the Spirit of Capitalism (New York, 1976).

48 Em seu famoso filme Tabu, Murnau mostra, de forma muito expressiva, como a introdução de dinheiro destrói uma sociedade arcaica.

${ }^{49}$ Cf. Ch. Payer, The Debt Trap: the IMF and the Third World (New York, 1974).
} 
todavia, de que os credores e devedores agora pertencem não a classes diferentes, mas a países distintos; e uma solução justa para esse problema, a meus olhos, não consiste em insistir no princípio formal e que as dívidas tem que ser pagas completamente. "Dívida por natureza" é uma boa alternativa.

O quarto e último argumento contra a situação atual é o seguinte: muitas das necessidades que foram desenvolvidas nos países de terceiro mundo foram inclucadas pelo primeiro mundo, embora sua introdução só pudesse ter consequencias fatais para o terceiro mundo. Um exemplo é a propaganda de pão de centeio na África, a qual barateou as produções locais de milhete, sorgo e mandioca, embora poucos países africanos possam cultivar trigo economicamente ${ }^{50}$; logo a dependência em relação ao primeiro mundo cresceu. É claro, poder-se-ia argumentar que o consumidor permanece soberano em seu ou em sua decisão, mas é óbvio que o cidadão comum do terceiro mundo pode prever as possíveis consequências da mudança de seu gosto muito menos do que as companhias ocidentais com acesso mais fácil à informação. Quem sabe mais também tem mais deveres - tal princípio se aplica aqui também. Não é apenas culpa do terceiro mundo que a produção de alimentos é negligenciada em favor de artigos de exportação com os quais as elites do terceiro mundo financiam seu luxo. Seus parceiros no primeiro mundo - e é claro, também os consumidores que os financiam - têm parte na culpa, pois eles devem saber que, por sua demanda, estão destruindo a base de cada economia - a saber, a agricultura - nos países de terceiro mundo.

É impossível falar sobre o terceiro mundo sem endereçar a questão demográfica. Embora seja certamente mentira que já somos muitos para se alimentar e embora seja claro que a fome mundial seja resultado de distribuição e não de produção, duas coisas devem ser ditas. Primeiro, há limites à produção (assim como o fardo humano ao meio ambiente), e mesmo num mundo com distribuição ideal e povoado por vegetarianos ${ }^{51} \mathrm{o}$ problema Malthusiano cresceria logo, se não houvesse inspeção da taxa de natalidade $^{52}$. Em segundo lugar, é ingênuo conceber uma distrubiução ideal: dada a natureza humana e os mecanismos de distribuição que existem atualmente, é irrealista querer superar a fome sem checar a taxa de natalidade. Não obstante, é claro que, já no nível teórico, esse problema seja muito mais complexo do que outros. Uma penalização financeira duma família com mais de três crianças através de uma política de impostos

\footnotetext{
${ }^{50}$ Ver Lappé e Collins, World Hunger, 13.

${ }^{51}$ Além de possíveis direitos animais, a atual situação da comida no planeta é uma forte argumento moral pró-vegetarianismo.

${ }^{52} \mathrm{O}$ famoso Essay on the Principle of Population (Harmondsworth, 1970), de T. R. Malthus, é importante não somente enquanto a primeira análise detalhada do problema demográfico. Ele também é memorável por causa de sua crítica à ideias iluministas ingênuas de progresso.
} 
atingiria as crianças, as quais claramente não são responsáveis por terem nascido; e um convite à esterilização de todo homem ou mulher após ter dado vida a duas ou três crianças é, na mairia dos países de terceiro mundo, claramente considerado como a violação dum direito sagrado. De fato, não devemos nos esquecer de que mesmo se rejeitamos claramente a idéia (a qual não pode ser universalizada) de que há um direito natural de ter tantas crianças quanto se quer, dois problemas ainda persistem. Primeiro, não é necessáriamente justo dizer que cada casal tem o direito de ter dois filhos; pois não apenas indivíduos mas também culturas têm direitos. Quando estamos chocados com a taxa de natalidade na África, não devemos nos esquecer de que o primeiro mundo também teve crescimento comparável, e que é a Europa, e não a África, que já está populada de forma extremamente densa. Se todas as culturas fossem tratadas igualmente, aquelas que já pecaram contra auto-constrição demográfica apresentariam vantagem tremenda. Segundo, o número-limite da população mundial depende também de nossas necessidades. Podemos ser muito mais se consumimos menos; e há certamente algo profundamente moral na decisão de viver uma vida modesta, mas ter uma família grande. Não posso deixar de comunicar uma impressão que tive frequentemente em países de terceiro mundo: que as familias pobres com muitos filhos frequentemente pareciam conhecer uma felicidade alheia às famílias ricas com um filho só no primeiro mundo. Não obstante, estou convencido de que, sem uma racionalização de nosso comportamento demográfico, justiça e paz não podem ser adquiridos; o efeito da redistribuição social das chances - por exemplo, uma reforma agrária nos países do terceiro mundo - por exemplo, seria aniquilado em poucas gerações, se o crescimento demográfico continuasse sem ser conferido. Nesse contexto, a emancipação das mulheres em países de terceiro mundo é de máxima importância. Não menos relevante é maior justiça social, pois filhos são as únicas riquezas dos pobres. Existe, todavia, um claro círculo vicioso; pois a racionalização do comportamento demográfico depende da introdução de justiça social, e isso é praticamente impossível sem controles no crescimento demográfico.

Todos os argumentos contra a justiça alegada da ordem econômica mundial atual, infelizmente, ainda não nos mostram o que deve ser feito. Pode-se concordar que muito dinheiro e muitas comodidades fluem do terceiro mundo para o primeiro e muito pouco na direção oposta, mas isso não resolve o problema central: para quem o dinheiro deveria ser dado? Que muito da ajuda desenvolvimental apenas deixou os ricos dos países de terceiro mundo ainda mais ricos e mais corruptos é, infelizmente, inegável; e certamente não é moral dar dinheiro apenas para acalmar a própria má consciência.

Com relação à segunda questão sobre a quem se deve direcionar a ajuda, vejo dois criterios moralmente relevantes: primeiro, as pessoas mais carentes deveriam recebê-la. Segundo, as pessoas mais propensas a ser 
multiplicadoras da ajuda são canditatos plausíveis, pois a meta final da ajuda deve ser chegar a um momento em que a ajuda se torna supérflua; não deve alimentar a inércia. Os dois grupos geralmente não coincidem; crianças carentes nas favelas e funcionários responsáveis do governo formam os dois extremos. No meio eu veria cooperativas em nível local. No caso de governos corruptos, ajuda intragovernamental não deve continuar, e o primeiro mundo não deveria evitar condenar o que deve ser condenado - o que, é claro, é muito mais fácil caso não se tenha promovido corrupção por um longo tempo. Parece-me que o paternalismo é um mal menor do que a indiferença; o país que ajuda tem o direito de ligar sua ajuda a condições, se e apenas se essas condições são interessantes para o país em desenvolvimento. Não apenas o direito à corrupção não encontra espaço aqui; o direito de errar termina quando o bem-estar de milhões depende em não errar.

No que tange às estruturas políticas internas dos países de terceiro mundo, parece-me justificado que o primeiro mundo promove democracias estáveis e eficientes. Todavia, não se deve esquecer que a democracia, para funcionar, pressupõe uma mentalidade baseada no respeito pela lei e pela ordem; onde não é o caso, facilmente torna-se desfuncional. Embora haja argumentos a priori para a superioridade da democracia, isso não implica que, para cada cultura com o mesmo nível de desenvolvimento, a democracia seja o melhor sistema político. Um bom estado garante também seguranca e direitos econômicos fundamentais; e, infelizmente, não é excluído a priori que esses direitos, por certo tempo, são mais bem cuidados por governos não democráticos. Na China, menos pessoas passam fome do que na Índia, e seria profundamente imoral considerar liberdade de expressão o único critério relevante pelo qual se julgam governos de países de terceiro mundo. A Europa foi dominada por monarcas durante séculos e, de acordo com a tese de Tocqueville, somente absolutismo esclarecido poderia destruir o feudalismo e, desse modo, preparar a democracia ${ }^{53}$. Um governo autocrático que supera certas injustiças sociais pode ser melhor que uma democracia na qual o governo é claramente corrupto e tanto as elites quanto as massas carecem das virtudes públicas necessárias para uma democracia. É verdade, todavia, que no mundo atual, especialmente após a crise do comunismo, democracias cada vez mais consideradas os únicos sistemas políticos legítimos. Uma oportunidade resultante do fim da Guerra Fria é que um consenso internacional dos países mais poderosos no que diz respeito à avaliação moral dos governos de terceiro mundo poderia ser adquirido, desde que a avaliação, esperançosamente, não seja mais enviesada por medos estratégicos em relação ao equilíbrio Leste-Oeste. Mesmo intervenções sancionadas internacionalmente para se livrar dos governos mais repudiantes do mundo são, a meus olhos, legítimos - caso

53 A. R. de Tocqueville, The Old Regime and the French Revolution (Garden City, 1955). 
sejam motivados por interesses da maioria do país de terceiro mundo em questão.

Para falar brevemente de política internacional, é de fato óbvio que precisamos duma Nova Ordem Mundial. Uma pluralidade de centros soberanos (os quais, para se tornarem realmente soberanos, devem necessariamente lutar para conseguir armas de extinção em massa) não é compatível com uma paz duradoura, e tanto a interdependência da economia mundial quanto o desafio ecológico pedem cada vez mais por decisões em nível global. Quem quer que tenha entendido o elo entre guerra e fome, deve ter esperança de que os países de terceiro mundo evitem guerras uns contra os outros. Mesmo uma pax Americana-Sovietica foi melhor do que anarquia internacional. A primeira condição de tal paz é, é claro, parar com a exportação de armas para países do terceiro mundo; só após isso o primeiro mundo adquire direito à intervenção. $\mathrm{O}$ imperialismo é uma palavra feia, mas a indiferença em relação aos problemas globais do mundo é ainda pior; e se certos problemas não podem ser resolvidos no nível nacional, a fundação de estruturas internacionais capazes de endereçá-las é um direito e até um dever para todos os estados responsáveis. O fim da Guerra Fria nos dá, de fato, a chance duma nova ordem internacional a partir da qual o mundo inteiro poderia lucrar. Mas como seria estruturada tal ordem? Ela substituiria o confronto entre países capitalistas e socialistas por um confronto entre os que possuem e os que não possuem? Tornar-se-ia a cortina de ferro entre Leste e Oeste a cultura de ouro entre Norte e Sul? Ou a nova ordem mundial endereçaria os problemas verdadeiros do mundo moderno, tentando superar a pobreza em massa e a ameaça a nosso ambiente comum?

Mas é claro que o problema principal na relação entre o primeiro e o terceiro mundo não é nem o econômico, nem o político - é cultural. Tem o primeiro mundo o direito de planejar uma nova ordem mundial, mesmo se considera os interesses do terceiro mundo muito mais do que fez no passado? É realmente legítimo desejar uma sociedade mundial construída de acordo com valores ocidentais? Eu penso que a resposta correta para essa questão deve evitar dois extremos. Um deles é o relativismo cultural. Por mais progressivo que possa soar, seu resultado definitivo é a negalção de que possa haver normais morais em relações interculturais e isso não é muito melhor do que o positivismo do poder. Também a idéia de que devemos respeitar cada cultura tal como é - mesmo se seu sistema de valores inclui a mais espalhafatosa violação de direitos - não apenas impraticável, é também inconsistente teoricamente. Pois pressupõe autodeterminação como o maior valor, e isso é um dos valores mais ocidentais. O relativismo cultural como ideologia pode muito bem ser a última consequência do imperialismo cultural do ocidente.

Do outro lado, é claro que temos que olhar com grande suspeita nossa própria cultura. É a cultura ocidental que trouxe à humanidade à beira 
de um desastre ecológico; e é nosso estilo de vida que não é universalizável e, portanto, imoral. Compreende-se muito quando se vê, por exemplo, que a corrupção no terceiro mundo, um dos fatores mais repelentes dessas culturas e uma das mais profundas causas pela pobreza em massa, resulta do desejo desesperado das elites do terceiro mundo de nos imitar. O primeiro mundo tem o direito de ter nojo da corrupção, mas apenas se o reconhece - como num espelho distorcido - a caricatura de si mesmo. Se o Ocidente não mudar seu sistema de valores, se não construir uma economia a qual seja mais justa no nível social quanto compatível com a preservação do meio ambiente, priva-se do direito de ensinar às outras culturas o que fazer. As ideias universalistas da moralidade são um progresso substancial do qual devemos nos orgulhar; a autonomia crescente e aceleração da tecnologia será autodestrutiva se não for controlada por princípios morais. Isso se aplica a nós e, ainda mais, aplica-se a culturas as quais ainda não possuem a mentalidade para usar tecnologia.

A expansão da cultura ocidental devia se preocupar primariamente com a extensão da moralidade universalista; pelo contrário, a tecnologia é dominante, gerando necessidades absolutas além de qualquer medida humana Mas mesmo no nível moral estrito, deixe-mo-nos tentar entender moralidades diferentes antes de condená-las. É claro, o infanticídio praticado por muitas culturas arcaicas não foi a forma certa de resolver o problema demográfico; mas a racionalidade por trás disso foi o insight de que as taxas de nascimento e de mortalidade devem estar em certa proporção caso se queira que o ecossistema sobreviva. Esse insight, como tantos insights contidos em mitos de outras culturas, não deve ser perdido. Estou longe de crer que o mito e a ciência tem a mesma pretensão de verdade, mas estou convencido de que o mito aborda a realidade de forma holistica, o que tem algumas vantagens comparado ao modo setorial, analítico de se pensar peculiar à ciência. $\mathrm{O}$ mito ainda não distingue entre ordem causal e eidética, mas uma era que é interessada apenas em análises causais pode ser lembrada, pelo mito, de que valores também devem ser endereçados. O mito reconhece que humanos são parte do cosmos - um insight quase esquecido pelo subjetivismo moderno. A pobreza em massa pode ser superada - mas reconheçamos, com admiração, as virtudes às quais educou muitas das pessoas do terceiro mundo. $\mathrm{O}$ encontro com sua vitalidade e solidariedade frequentemente nos dá a forca para superar o narcisismo de muitos habitantes do primeiro mundo.

Se a diversidade cultural não conflita com a ideia do direito ou com o interesse comum dos humanos de sobreviver juntos nesse planeta, deve ser reconhecido como valor e também protegido como tal, e até mais do que a biodiversidade. As culturas são reservatórios de formas de expressão, assim como de representações simbólicas, e desde que não há uma forma de representar e de expressar a verdade, cada tentativa de fazê-lo merece ser preservada. $\mathrm{O}$ orgulho pela própria cultura pode se tornar perigoso, caso 
previna os membros dessa cultura de reconhecer os valores das outras culturas, e eu não sou cego aos perigos do programa antiocidental mais poderoso politicamente, o fundamentalismo islâmico. De outro lado, se a ideologia consumista do Ocidente não deva ser imitada, voltar às próprias raízes pode ser uma das formas de se superar tal dependência com maior êxito. As elites que lutam pelos interesses legitimos de um país são melhores do que aquelas que só querem tomar parte nos luxos do Ocidente. Nunca devemos nos esquecer de que a cultura islâmica da Idade Média adquiriu um nível de universalização e de esclarecimento superior à do cristianismo contemporâneo; al-Farabi não tinha par no Ocidente de seu tempo. Estudemos seu trabalho ${ }^{54}$ e lembremos aos muçulmanos do nível de universalismo que eles tinham no passado, ao invés de condescender em clichês banais da cultura islâmica. A cultura islâmica declinou porque ignorou as aquisições do Ocidente; evitemos o mesmo destino.

A categoria principal nas relações interculturais é, é claro, a identidade. A identidade pessoal e cultural claramente significam algo diferente da identidade tautologica $A=A$, a qual nunca é um problema, enquanto a busca pela identidade frequentemente o é. Eu não posso discutir o problema na profundidade que ele merece; mas eu quero terminar nomeando três momentos necessários de qualquer busca racional pela identidade. Primeiro, um elo com idéias universais é necessário; qualquer identidade que nega esse elo é fadada a se tornar patológica e parasítica. Existem, todavia, formas diferentes de se dar conta do universal; e a própria capacidade de alguém é geralmente determinada pelo seu passado, seja ele individual ou coletivo. Quem quer que ignore sua história falhará em encontrar uma identidade razoável ; a própria história de alguém é, portanto, o segundo momento na busa da identidade. Mas o indivíduo pode encontrar o seu ou a sua identidade peculiar apenas confrontando-a com outras identidades; e o sentido mais profundo do amor é, obviamente, encontrar uma identidade estável e moral. Agora, esse aspecto intersubjetivo não se aplica apenas a relações interpessoais; ele é válido também para relações interculturais. $\mathrm{O}$ confronto com outras culturas pode ser traumático; mas também pode levar a um desenvolvimento no qual uma cultura é plenamente realizada. Deixe-me terminar com uma história que ilustra habilmente meu posicionamento. Em Tales of the Chassidim, coletado por Martin Buber, encontramos a história do pobre rabi Esik, filho de Jekel, que estava morando na Cracóvia. Ele foi perseguido muitas evzes por um sonho o qual o incitou a ir a Praga; sob a ponte principal ele encontraria um tesouro. Finalmente, o rabi deixa a Cracóvia; após chegar a Praga, ele observa, por muitos dias, os soldados que observam a ponte. Eventualmente, o capitão dos soldados o endereça, e Eisik conta-lhe sobre seu sonho. Mas o

\footnotetext{
${ }^{54}$ Tenho em mente, especialmente, R. Walzer, ed., Al-Farabi on the Perfect State (Oxford, 1985).
} 
capitão o desdenha; ele mesmo, ele responde, é atormentado por um sonho semelhante, ir à Cracóvia e procurar por um tesouro no canto, atrás do forno de um pobre rabi chamado Esisik, filho de Jekel. Mas ele nunca levaria tal sonho a sério. Você está certo, responde o rabi, que retorna a seu lar, onde encontra o tesouro prometido no sonho ${ }^{55}$.

Eu não gosto do momento assimétrico na estória, mas estou convencido de que nos ensina algo com o qual eu quero concluir: o primeiro mundo não superará sua crise de identidade se não começar a procurar e respeitar a identidade do terceiro mundo.

${ }^{55}$ Encontrei essa história em H. Zimmer, Myths and Symbols in Indian Art and Civilization, ed. J. Campbell (New York, 1963), 219ss. Zimmer cita M. Buber, Die Chassidischen Bücher (Hellerau, 1928), 532ss. 